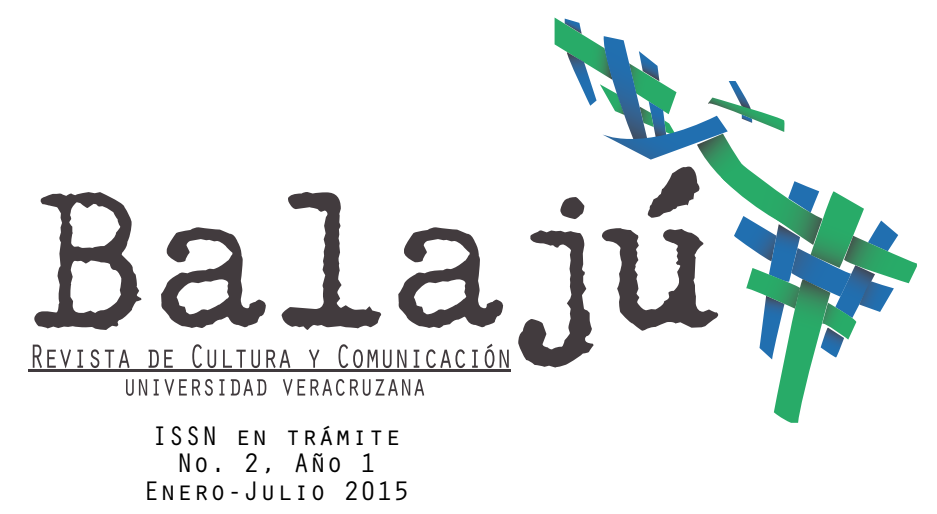

Balajú, reinvención académica de la Cultura y la Comunicación

Raciel D. Martínez Gómez*

Universidad Veracruzana, México

racvega@hotmail.com

*Doctor en Sociedades Multiculturales y Estudios Interculturales. Director General de Comunicación Universitaria de la

Universidad Veracruzana 


\section{Balajú, reinvención académica de la Cultura y la Comunicación}

Primeramente quiero agradecer la invitación para presentar el número 1 de Balajú. Revista de cultura y comunicación de la Universidad Veracruzana. Agradeceré en específico al grupo de investigadores que pertenecen al Centro de Estudios de la Cultura y la Comunicación de la Universidad Veracruzana el esfuerzo por visibilizar el trabajo en equipo que han realizado en los últimos seis años. Además, agradezco el tono interdisciplinario y la gran apertura con los que apuestan en sus lecturas del mundo contemporáneo. Y también quisiera agradecer y reconocer la modernidad de este grupo de investigadores que ha decidido utilizar un medio digital que permite, como dice la doctora Celia del Palacio Montiel en la presentación de Balajú intitulada Para empezar a cantar, mucha mayor visibilidad y accesibilidad que los soportes impresos.

Como parte de esta presentación, decidí que sería interesante ubicar el esfuerzo de comunicación en un contexto de la comunicación como disciplina, y en medio del torbellino de cambios que ha padecido a consecuencia de una implosión tecnológica de alternativas que han modificado los modelos comunicacionales. Posteriormente y, para finalizar, destacaré entonces algunos elementos propios de Balajú que la distinguen, desde este primer número, como un espacio académico donde la cultura y la comunicación son analizadas con un altísimo nivel de profesionalismo ético y formal, y cuyos contenidos revelan preocupaciones varias que van desde detalles lúdicos -como el que plantea Rafael Figueroa para dar cuenta del origen de la palabra balajú- hasta un estudio comprometido políticamente hablando -como el que publica la doctora Del Palacio con relación a las agresiones a los periodistas, en la sección bellamente intitulada Ariles y más ariles, esos sueños que además se interconectan en la propia melodía del Balajú.

Vamos entonces con un poco de epistemología e historia para valorar la presencia de la revista Balajú en un inasible campo de estudio como el de la comunicación.

El objeto de la comunicación ha tenido serias transformaciones en su novel vida como campo de estudio académico. Muchos han afirmado que la comunicación es una ciencia puente, que entrelaza varias disciplinas para abordar los complejos epifenómenos derivados de la comunicación de masas que apareció como tal en la década de los veinte del siglo pasado. 
Pero habría que matizar que ciencia puente no lo es porque, para empezar, no es estrictamente ciencia, sino más bien es, a todas luces, una disciplina. En cuanto a lo del puente, no estaría del todo seguro que lo fuese, aunque concursen en el currículo de formación en carreras y posgrados disciplinas como la sociología, la filosofía y la antropología para que, desde sus teorías y sobre todo metodologías, se estudien problemas de comunicación.

Tal vez podríamos postular que estaríamos hablando, en todo caso, de que la mayoría de las disciplinas, concretamente las de la mal llamada área de Humanidades, son en sí mismas puentes, porque cada una en diferentes momentos recurre a otras para explicarse, para darse a entender, para investigar y justificarse, nutriéndose entre sí para olvidar esa idea del conocimiento parcializado.

Ahora bien, se discutió durante cierto tiempo -quizás una década entera- que el objeto no sólo se centraba en la comunicación de masas, porque es evidente que había más hechos diferenciados que se podían analizar como actos de comunicación y que no necesariamente estaban vinculados a la emisión y recepción en la comunicación masiva; prácticas, pues, que se salían de alguna manera de dicho circuito dominado por una mirada macro y sociológica que, en mi opinión, ha impedido apreciar precisamente las prácticas culturales concretas tanto de los grupos como de los individuos, mismas que en Balajú, está claro, son el horizonte de trabajo.

Jesús Martín-Barbero y Daniel Prieto Castillo han abonado, con gran lucidez, la especie de que la comunicación tiene como objeto un campo amplio de acciones y hechos comunicativos. Martín-Barbero ha señalado desplazamientos del modelo de comunicación rígido que subrayan la arbitrariedad de los receptores para transformar los mensajes. Prieto Castillo, por su parte, con su categoría de comunicación alternativa descentra la idea de la comunicación en lo masivo para reconocer otras prácticas en la sociedad civil.

Lo que hicieron entonces Martín-Barbero y Prieto fue, digámoslo de alguna manera, darle carta de mayoría de edad a esa masa, darle un rostro humano y reconocer en la cultura popular acciones de resignificación arbitraria que derrotaban las tesis implícitas y explícitas tanto de funcionalistas como de marxistas que pensaban que el receptor era un ente pasivo que no tenía capacidad de respuesta.

Lo anterior ha quedado ampliamente rebasado, pese a que varios personeros en el poder y en las instituciones sigan postulando que los efectos de la comunicación pueden darse como lo proponía la Teoría de la aguja hipodérmica de Harold Lasswell. No me detendré en lo que ca- 
lifico como debate bizantino, pero diré que ese enfoque desde diversos niveles del conocimiento ha sido desmontado, y prueba de ello es la aparición de la revista Balajú, que todo sostiene, menos que los públicos sean entes inermes a la propaganda.

La globalización fue el hecho o la circunstancia sociopolítica que de plano ensanchó el objeto de estudio de la comunicación. El modelo que más o menos operó para explicar lo que ocurría en la comunicación, desde los funcionalistas de Chicago hasta los marxistas latinoamericanos, se agotó a mediados de la década de los ochenta.

Y es que la aparición de una nueva plataforma tecnológica modificó sustancialmente el modelo de comunicación y abrió la posibilidad de que el receptor se ubicara como perceptor e, inclusive, como emisor en un contexto de democratización de las opciones de respuesta y en un mundo donde las redes sociales comprueban el hambre de cambio de los individuos en apariencia alienados por una sociedad de consumo.

Hoy sin ningún tapujo se habla de cultura y comunicación debido a esta modificación radical del modelo de comunicación.

Sabemos que hay antecedentes diversos en las publicaciones de cultura y comunicación. El semiólogo argentino Héctor Schmucler fundó en la década de los setenta la revista Comunicación y Cultura al lado de teóricos como Armand Mattelart y Ariel Dorfman. Comunicación y Cultura publicaba desde el propio Schmucler y sus célebres críticas a la era de los satélites, Javier Esteinou Madrid y sus aparatos hegemónicos del estado hasta las disquisiciones de la rumba de Froylán López Narváez.

En este sentido, Balajú se ubica dentro del Catálogo de Revistas de la UV y está ya en el blog universitario junto a otras 11 revistas como Clivajes, CPU-e, Energeia, Investigación Teatral, Orientando, Psicología y Salud, Revista Electrónica Medicina, Salud y Sociedad, Stoa, Ulúa, Universos Jurídicos y UniverSalud.

Destacan los artículos de este primer número por una búsqueda novedosa de las cosas en un contexto de dinámicas culturales complejas, tal y como lo consigna Raquel Guerrero Viguri en su interesante análisis sobre la webnovela.

Si bien hay un rigor académico en la sintaxis de todos los textos, también se percibe un tono más flexible. No se detecta en el corpus temático una presunción sino, más bien, un claro propósito de ir entre los meandros precisamente culturales, a diferencia de esas revistas de comunicación y cultura que respondieron a causas ideológicas de envergadura macrosocial, soslayando lo que Balajú se propone contarnos. Muchos dirán que eran los tiempos, pero yo diré que era la ausencia de una perspectiva, justamente, cultural. 
De tal forma que en Balajú encontramos otro artículo como el de Ricardo Pérez Montfort, que es muy ilustrativo de esta postura interdisciplinaria y puesta en escena en los intersticios de lo objetivo y de lo subjetivo. Y es que el ensayo de Pérez Montfort es muy honesto al respecto ya que, acudiendo a la premisa de Peter Burke de que no existe acuerdo para narrar una historia cultural, recomienda partir desde un ángulo particular. Entonces Ricardo admite caer en la tentación de contar una historia de los vínculos particulares y personales con aquella esfera llamada historia cultural. El resultado es un relato de formación y trayectoria intelectual de lo más entretenido, porque Ricardo es un ejemplo excelente de cómo las disciplinas se traslapan, se imantan, y de cómo la variedad laboral enriquece la mirada del historiador Pérez Montfort con un enfoque de comunicólogo y de cómo se renueva constantemente la mirada sin ningún temor a la falta de congruencia.

Otro artículo digno de resaltar es el de Gustavo Lins Ribeiro, en el que debate acerca de cómo la diversidad cultural se ha transformado en un discurso de las élites comprometidas con la cooperación internacional y con la gobernanza global. Incluso, confía Lins en la capacidad actual que tiene la diversidad cultural para construir un amplio consenso. Y, en efecto, la diversidad cultural es un tópico de coyuntura que ha evidenciado la incapacidad de las disciplinas que no estaban del todo preparadas para esta acelerada visibilización de sentidos culturales a través de las nuevas tecnologías de la información. El texto nos muestra que la llave para entender el mundo contemporáneo está en la diversidad cultural, y ya lo que se encuentre adentro de esta gran casa mundial es asunto por matizar. Pero de que la diversidad cultural es una categoría indispensable para comprender la gobernanza global, no tiene desperdicio alguno.

Asimismo me agradó el texto de María Soledad León Torres intitulado "La pérdida de una hija: género y matrimonio en un contexto de migración internacional”, por su aporte etnográfico y su bien resuelta interpretación y argumentación de la misma.

En lo que respecta al artículo "La significación del nombre", los autores Norma Esther García Meza y Daniel Domínguez Cuenca nos recuerdan qué tan caprichosa es la memoria de los otros que trasciende en variadas ocasiones los significados lingüísticos y los epistemológicos. Los testimonios que se recogen en este artículo enfatizan esta arbitrariedad cultural que ahora sí exploran los estudios de la cultura y la comunicación.

Y también de Domínguez Cuenca está la reseña del libro Lenguajes de la cotidianidad, coordinado por Gabriela Sánchez Medina y Norma Esther García Meza, en un gratísimo esfuerzo de cuerpos académicos de 
la Universidad Michoacana de San Nicolás de Hidalgo y de la Universidad Veracruzana por ofrecer un mosaico de análisis discursivos con una buena y creativa cantidad de metodologías que enseñan los diferentes caminos de abordaje de este nuevo matiz del campo comunicativo.

En fin, esperamos que Balajú, y la verdad estoy seguro que así lo harán sus editores, se reinventará cada vez que aparezca un nuevo número, haciendo honor entonces a esa estructura abierta del son, pues por mucho, aunque sea formalmente, es la silueta sotaventina la que distingue a este enfoque regionalista que aspira a ser global. Felicidades de nueva cuenta para quienes se empeñan en hacer del trabajo académico, también, un deleite del conocimiento. 